\title{
The influence of organizational justice on corporate performances
}

\author{
Biljana Đorđević \\ University of Niš, Faculty of Economics, Niš, Republic of Serbia \\ Maja Ivanović-Đukić \\ University of Niš, Faculty of Economics, Niš, Republic of Serbia \\ Vinko Lepojević \\ University of Niš, Faculty of Economics, Niš, Republic of Serbia \\ Sandra Milanović \\ University of Niš, Innovation Center, Republic of Serbia
}

\begin{abstract}
Professional and committed employees have always been a desirable resource in the portfolio of human resources of each company because their expertise and engagement can significantly affect the overall performance of businesses. The readiness to put the potential that have in the function of the company is, however, under the influence of a variety of factors, starting from the design of the job, through the reward system, to the possibility of promotion. As one of the most important factors, which is not sufficiently addressed in domestic literature, is the perception of organizational fairness, as well. This category refers on the degree to which employees believe that the decisions made in the company are fair, the procedures that are applied are fair, and the treatment of the employees to whom the decisions are made for are fair. Numerous empirical researches have shown that when a higher level of organizational justice is perceived in the company, it has a positive impact on the manifestation of organizational citizenship behaviour, job satisfaction, commitment, etc. Since all these forms of employees' behaviour and attitudes are positively correlated with individual, and thus overall, organizational, performances, organizational justice could be seen as one of the factors that can influence the performance that the company as a whole. Bearing in mind the above, the subject of the paper is to examine whether organizational justice has a statistically significant impact on the performance of companies in Serbia, and to what extent some forms of organizational justice (distribution, procedural and interactive) affect them. The aim of the paper is to propose mechanisms and measures based on the results of the research to managers, whose implementation can contribute to the increase of organizational justice in those segments that are poorly assessed. The starting assumption of the paper is that organizational justice has a statistically significant impact on company performance. In order to verify the validity of this assumption, the methods of correlation and regression analysis will be used. The analysis will be based on the data obtained from the primary research carried out in the companies mostly in the South East of Serbia. The theoretical implications of the paper are reflected in filling in the gaps in domestic literature regarding organizational justice and its possible implications, while empirical implications are reflected in the ability to increase the level of justices in the companies in Serbia by applying the proposed mechanisms and measures and thus positively influence attitudes, behaviour and performances of employees.
\end{abstract}

Keywords

Organizational justice, performances, employees, enterprise.

\section{Introduction}

It is a long-known fact that human resources are the bearers of working potential that can be used for achieving the organizational goals. However, to what extent this potential will really be used for their realization depends on a number of different factors. Numerous empirical studies have showed that the willingness of employees to put their competences at the disposal of the company is influenced by: job design (Garg \& Rastongi, 2006; Sharon \& Kubala, 2018), reward system 
(Rynes, Gerhart, \& Minette, 2004), possibilities of promotion (Njambi, 2014), quality of interpersonal relationships (Martin \& Dowson, 2009), etc. However, one of the factors that draw attention for the last 20 years is organizational justice as well. This category refers on the degree to which employees consider that decisions, procedures and interactions in the workplace are fair (Adams, 1965; Leventhal, 1976; Bies \& Moag, 1986; Greenberg, 1987; Baldwin, 2006). Accordingly, there are three types of organizational justice that differentiate in the literature: distributional, procedural, as well as interactional justice.

By studying the organizational justice many authors came to the conclusion that this is a very significant phenomenon that has a strong influence on the attitudes and behaviour of employees. In that line it has been found that organizational justice affects the level of employee commitment (Hassan, 2002), their willingness to manifest organizational citizenship behaviour (Jafari \& Bidarian, 2012), job satisfaction (Al-Zu'bi, 2010), motivation (Latham \& Pinder, 2005), etc. The explanation for influence of perception of justice on motivation Latham and Pinder (2005) found in the fact that employees' motivation often stems from the interaction between individuals, as well as between individuals and the environment, i.e. situations that are also important for judgment on organizational justice.

As all of the aforementioned phenomena are positively correlated with the performance of employees (Khan, Ziauddin, Jam, \& Ramay, 2010; Bin, 2016; Basu, Kumar Pradhan, \& Ram Tewari, 2017), and, thus, with the overall organizational performance, the importance of the concept of organizational justice is not questioned. Furthermore, despite of the fact that this is a quite often investigated topic in the literature, there is a still need for deeper studying of this category.

Starting from the above, as well as from the fact that organizational justice is not sufficiently studied in domestic literature, the subject of this paper is to examine the impact of this category on the performance that enterprises in Serbia realize. The aim of the paper is to suggest certain mechanisms and measures to the managers of domestic enterprises whose implementation can contribute to increasing the level of organizational justice in their enterprises and, consequently, make a positive impact on the results that those companies achieve.
The paper is structured as follows: in the first part of the paper the review of the literature on the concept of organizational justice is given and starting hypotheses are defined. The second part gives an overview of the results of the research and presents their discussion, while concluding remarks are given at the end of the paper.

\section{The review of literature on organizational justice and development of hypothesis}

The topic of justice in the literature is not new. The beginnings of studying of this category can be found in the ancient Greece (Cropanzano, Bowen, \& Gilliland, 2007). In management, however, this topic begins to be studied in the $60 \mathrm{~s}$ of the twentieth century. However, unlike the ancient Greeks who studied what is essentially fair, the authors in the field of management study what people (employees) believe that it is fair (Cropanzano et al., 2007). Consequently, organizational justice in management literature is defined as the degree to which employees consider that decisions, procedures and interactions in the work environment are fair (Adams, 1965; Leventhal, 1976; Bies \& Moag, 1986; Greenberg, 1987; Baldwin, 2006).

The topic of organizational justice in an enterprise is usually analysed in the situations where adverse employment occurrences happen, such as, for example, dismissal of employees. However, the question of fairness is also important in many other situations and processes that occur on a daily basis in enterprises, especially those that fall within the domain of human resources management. It that regard, the question of organizational justice is important when it is about the performance assessment, rewarding, resolving conflicts, selecting candidates, hiring, etc. (Baldwin, 2006).

Employees as individuals usually judge fairness in the company when they are personally affected. In order to evaluate whether a situation/event was just or not, they compare this situation/event with a referent situation that serves as a "criterion of fairness" (Cropanzano et al., 2007). If employees consider that there is a negative deviation, this event will most likely be assessed as unfair. In such situation, there may be many negative consequences for employees, such as: stress, intention to leave the organization, withdrawal of professional energy from everyday activities, disgrace, etc. (Turnley \& Feldman, 1999). All these situations further can have 
negative consequences, both in terms of their performance, and the results that companies achieve.

Bearing in mind that a high level of organizational justice has a positive impact on phenomena such as organizational commitment, organizational citizenship behaviour, etc., and that the low level of justice is associated with negative occurrences and outcomes in the work environment, the hypothesis $\mathrm{H} 1$ that we are going to test in our study is as follows:

H1. The relationship between organizational justice and company performance is direct and statistically significant.

Organizational justice is not, however, a onedimensional concept. Most authors consider this category as the constellation of three types of justice: distributive justice, procedural justice and interactional justice. Some authors also distinguish additional types of justice. Within the framework of interactional justice they distinguish interpersonal and information justice (Colquitt, 2001). However, for the needs of this paper we will observe organizational justice as a composition of three basic types of justice.

When it comes to distributive justice, it is, in the broadest sense, related to whether people estimate what they received from the organization as fair or not (Cropanzano \& Molina, 2015). This form of organizational justice was the first that draw the attention of the authors and has been the subject of numerous researches (Cropanzano \& Molina, 2015). It has theoretical foundation in two concepts: Adam's equity theory (1965) and the justice judgment model of Leventhal (1976).

The basic components of Adam's theory of justice (1965) are inputs and outputs. Inputs are seen as the contribution of individuals, while outputs are seen as the rewards that individuals received on the basis of their contribution. According to this concept, the reward allocation should be in line with the contributions of those who will receive the reward. Speaking of the relationship between inputs and outputs, Baldwin (2006) suggests that outputs can take the form of earnings, advancements, career development opportunities, job security, etc., while inputs relate to employee commitment, level of education, participation in training programs, experience, etc. The same author, further, states that since it is difficult to determine which level of reward follows a precisely determined level of input, judgment on the conveyance of reward distribution is based on relative comparison. In other words, employees assess distributive justice whether the same rewards are distributed for the same level of input for all employees in the company (Baldwin, 2006).

Another concept that also forms the foundation of the theory of distributive justice is Leventhal's justice judgment model (1976). The basic characteristic of this model is that when it is about the assessment of justice, the decision in not made only on distribution rule as it is in Adam's model, but on two additional rules: the rule of equality and the rule of needs. However, in different situations, more emphasis can be given to the certain rule, which makes this theory dynamic, unlike Adam's, which is considered to be static. According to the justice judgment model, individuals evaluate the fairness of decisions on the following rules (Leventhal, 1976):

- Contribution rule - this rule implies that the results of decisions are allocated in accordance with the contribution of individuals;

- Rule of equality - implies that equal contributions should be followed by an equal rewards;

- Rule of need - this rule means that those with higher needs need to receive a higher reward (for example, if spouses work in the same company, it should recognize their special needs when it is about using the annual leave, when making the schedule of work, etc.).

If employees consider that decisions made by the company are not fair, the negative affective, cognitive and behavioural reactions will occur (Cohen-Charash \& Spector, 2001). In other words, the employees will be anger, dissatisfied and probably will reduce the level of engagement in order to establish a new ratio between inputs and outputs (Cohen-Charash \& Spector, 2001). On the other hand, if distributive justice is perceived at a high level, employees can be expected to be more satisfied, motivated and more committed to the organization. This, furthermore, can lead to their higher performance, and thus overall organizational performance. Bearing in mind the above, the hypothesis $\mathrm{H} 2$ that we are going to test is as follows:

H2. Distributive justice has a positive and significant impact on company performance.

Procedural justice refers to the perception of the fairness of the procedures when decisions were made as well as during their implementation. 
This phenomenon also has great importance for the attitudes and behaviour of employees and in some situations even greater than distributive justice has. Namely, it turned out that employees would be more willing to accept unwanted outcomes if they felt that the decision-making process was based on the principles of fairness. Practice has shown that employees consider procedural justice at a higher level if, before making a decision, they are given the opportunity to express their opinion or to communicate relevant information (Baldwin, 2006).

The perception of a higher level of organizational justice will occur if the Leventhal's rules (1976) are followed. These rules are:

- Consistency. This rule means that the same procedures should be applied to all employees, and that these procedures should be stable over a longer period;

- Bias suppression. This rule implies that the allocation process must be based on an objective basis that excludes any subjectivity and bias;

- Accuracy of information. This rule implies that the process of allocating of the outputs must be based on information and objective facts which minimize errors;

- Correctability. This rule means that modifications of procedures and processes should be enabled in case of need;

- Representativeness. This rule requires that, when implementing the procedures, the attitudes, values and perspectives of all the entities to which the process refer, should be taken into account;

- Ethicality. The rule of ethics implies that the processes in organization must be compatible with basic moral and ethical values and standards.

Speaking of the impact of procedural justice on the attitudes and behaviour of employees, some authors state that if employees consider the distribution of decisions to be unfair, the first question put by the employees is related to the procedures that produced such decisions. If they conclude that the procedures were not fair, they will probably reduce their performance in order to re-establish the "new" justice in the company (Kalay, 2016). On the other hand, if the procedures are fair, this has a favourable impact on the social exchange that takes place in the company. Namely, if management has demonstrated a commitment to the principles of fairness, it is possible to expect greater loyalty, the emotional attachment of employees with the organization, their greater engagement, etc., which usually leads to higher individual's performances (Khan et al., 2010; Bin, 2016; Basu et al., 2017; Sponte Piştalu, 2018), as well as organizational performances. Based on the above the hypothesis $\mathrm{H} 3$ that we are going to test in the study is as follows:

H3. Procedural justice has a positive and significant impact on company performance.

The third form of organizational justice is interactional justice. Although some authors consider that fairness in interactions falls within procedural fairness, thanks to its importance, some authors state that it can be viewed as a separate form of organizational justice (Bias \& Moag, 1986). Namely, Bias and Moag (1986) state that in addition to the fact that employees evaluate fairness in the organization on the basis of some objective events and procedures, they evaluate fairness through social and communication criteria as well. Accordingly, these authors consider that it a justifiable to make distinction between fairness in interpersonal relations and fairness in the field of information.

Generally speaking, fairness in interactions relates to the attitude towards employees working in a company whether it is respectful (Baldwin, 2006). Bias and Moag (1986) have formulated certain principles whose implementation can contribute to the perception of higher level of fairness in interactions in the company. These are the following principles (Bias \& Moag, 1986):

- Truthfulness - this principle means that information provided to employees should be realistic, accurate and presented in an open (transparent) and honest way,

- Respect - this principle means that relation towards employees should be with dignity and without any signs of insult or discourteous behaviour,

- Propriety - the meaning of this principle is that relation and statements should never be inappropriate or include the intention to hurt someone on the basis of race or gender,

- Justification - this principle means that if some form of injustice occurs giving additional explanation or apology may reduce or eliminate the sense of anger.

Overall, considering and respectful relationship of management towards employees 
creates the felling of the employees that they are valuated and that they are an important part of the organization (Kalay, 2016). These positive feelings could encourage employees to reciprocate behaviour or even to demonstrate behaviour that go beyond their formal role (Nasurdin \& Khuan, 2011). This, furthermore, can positively affect the performance achieved by individuals as well as the overall organizational performance. Based on the above the fourth hypothesis we are going to test will be as follows:

H4. Interactional justice has a positive and significant impact on company performance.

\section{Sample and procedure}

In order to verify the validity of these hypotheses, a primary research was conducted. We examined how employees in the Republic of Serbia perceive certain segments of organizational justice and is there a link between organizational justice and business performance. The survey was conducted from October 2017 to February 2018, by interviewing employees in the organizations in the south east of Serbia. The questionnaire included two sets of questions. The first group was general questions about gender, age, education, length of service and employee position in the company. The second group was made of questions related to employee attitudes about certain segments of organizational justice. The questions were formulated in accordance with the questionnaire created by Neihoff and Moorman (1993). Employees were asked to score from 1 to 5 on Likert scale (1 means "I do not completely agree" and 5 "completely agree") each segment of justice in the organization. There were more questions to analyze the perception of every form of justice.

The sample included 200 employees in 17 organizations operating in the territory of the Republic of Serbia (mostly south-eastern Serbia). Out of the total questionnaires distributed, 31 were rejected due to incomplete answers, and 169 were retained. In the structure of the sample, women accounted for $42.0 \%$, while men were slightly higher and accounted for $58.0 \%$ of the respondents. As for the age structure, it was as follows: $10.1 \%$ consisted of respondents aged under $25,42.0 \%$ respondents between 26 and 40 years, $40.2 \%$ were respondents between 41 and $55,7.7 \%$ respondents older than 55 years. Also, $66.2 \%$ of employees have secondary education, $20.7 \%$ have high education, while $9.5 \%$ have higher education, and only $3.6 \%$ have elementary education.

\section{Results and discussion}

The values of Cronbach's Alpha of 0.913 indicate a very good reliability and an internal matching of scales in the sample. According to the data in Table 1, the Correlated Item-Total Correlation column, it can be concluded that there is a high degree of correlation of each item with total results. Since all values in the Cronbach's Alpha if Item Deleted column are less than the final alpha value (0.913), we find it is justified that all items in the existing scale remain, and that this scale is comparable to researches based on such a scale. Table 1 also shows that the correlation of the pairs of items ranges from 0.679 to 0.748 . This indicates that the correlation between the items is strong.

Table 1 Reliability of measurement scale

\begin{tabular}{l|c|c}
\hline \multicolumn{1}{c|}{ Items } & $\begin{array}{c}\text { Corrected Item- } \\
\text { Total } \\
\text { Correlation }\end{array}$ & $\begin{array}{c}\text { Cronbach's } \\
\text { Alpha if Item } \\
\text { Deleted }\end{array}$ \\
\hline Distributive justice &, 692 &, 829 \\
\hline Procedural justice &, 748 &, 880 \\
\hline Interactional justice &, 679 &, 827 \\
\hline Cronbach's Alpha &, 913 & \\
\hline Sample size & 169 & Source: Authors
\end{tabular}

Table 2 shows the average values of observed variables and deviations from the average. Based on the data in Table 2, it can be concluded that employees generally have a neutral attitude when it comes to organizational justice. Namely, organizational justice in enterprises is estimated at an average of 3.53, and the range of possible ratings ranges from 1 to 5 . The data in Table 2 also show that distributive justice is best scored (3.94), while procedural justice (3.28) and interactional justice (3.39) got some lower grades. 
Table 2 Descriptive statistics

\begin{tabular}{l|c|r|r|r|r}
\hline \multicolumn{1}{c|}{ Items } & Sample & \multicolumn{1}{c|}{ Minimum } & \multicolumn{1}{c|}{ Maximum } & \multicolumn{1}{c}{ Mean } & \multicolumn{1}{c}{ Std. Deviation } \\
\hline Productivity & 170 & 150637.22 & 33285371.59 & 8776149.2897 & 9581489.97698 \\
\hline Distributive justice & 170 & 1.00 & 5.00 & 3.9435 & .85802 \\
\hline Procedural justice & 170 & 1.00 & 5.00 & 3.2814 & .69497 \\
\hline Interactional justice & 170 & 1.00 & 5.00 & 3.3980 & .82890 \\
\hline Organizational justice & 170 & 1.00 & 5.00 & 3.5349 & .68671 \\
\hline Valid N (listwise) & 170 & \multicolumn{5}{l}{} \\
\hline
\end{tabular}

Source: Authors

For verification of the validity of upper hypotheses, a multiple correlation and regression analysis was performed. The dependent variable in the model was the productivity of labour, measured as income per employee, while the independent variables were perceived as the level of distributive justice, procedural justice, interactional justice and total organizational justice. The results of the correlation analysis are shown in Table 3.

Table 3 Correlation of organizational justice and productivity in enterprises in Serbia

\begin{tabular}{|c|c|c|c|c|c|}
\hline & Productivity & $\begin{array}{l}\text { Distributive } \\
\text { justice }\end{array}$ & $\begin{array}{l}\text { Procedural } \\
\text { justice }\end{array}$ & $\begin{array}{l}\text { Interactional } \\
\text { justice }\end{array}$ & $\begin{array}{l}\text { Organizational } \\
\text { justice }\end{array}$ \\
\hline Productivity & 1 &, $492^{* *}$ & ,401 & $347^{*}$ & $.435^{* *}$ \\
\hline Distributive justice & & 1 &, $588^{* *}$ &, $517^{\star *}$ & $.833^{* *}$ \\
\hline Procedural justice & & & 1 &, $719^{* *}$ & $.877^{* *}$ \\
\hline Interactional justice & & & & 1 & $.865^{* *}$ \\
\hline \multicolumn{5}{|l|}{ Organizational justice } & 1 \\
\hline
\end{tabular}

Source: Authors

The data in Table 3 show that there is an average, direct and statistically significant correlation $\left(0.435^{* *}\right)$ between organizational justice and business performance of organizations in Serbia, measured by labour productivity. In other words, increasing of the perceived degree of organizational justice leads to an increase in productivity and, contrary, the decline in the perceived level of organizational justice is accompanied by a decline in productivity. Having in mind that the correlation is a statistically significant, we can conclude that our first hypothesis has been proven.

The data from Table 3 show that the correlation between productivity of labour, on the one hand, and certain forms of organizational justice (distributive, procedural, and interactional), on the other hand, is also direct and medium strong. In addition, the relationship between distributive justice and productivity is statistically significant at a significance level of $0.01(0.492 * *)$. This means that increasing of perceived degree of distributive justice leads to an increase in productivity and, contrary, the reduction in the perceived level of distributive justice is accompanied by a fall in their productivity. In other words, if employees believe that what they receive from the organization is fair, estimated on the basis of their investment and engagement, they will do more and achieve greater productivity.

The data in Table 3, further, shows that the link between interactional justice and productivity is significant at the level of 0.05 , but significantly weaker compared to the link between productivity and distributive justice. This means that increasing the perceived degree of fairness in interactions leads to an increase in productivity and, conversely, the reduction in the perceived level of fairness in interactions is accompanied by a decline in productivity. In other words, if employees perceive that the level of appreciation of their personality is greater, that they are provided with relevant information, they will achieve greater productivity.

Finally, Table 3 shows that the correlation between productivity and procedural justice is direct and moderately strong, which means that increasing the perceived degree of procedural justice leads to an increase in productivity and otherwise. However, this connection is not statistically significant, so the conclusion cannot 
be generalized. The reason for this situation can be explained by the fact that the Serbian national culture is characterized by a great distance of power (Hofstede, 1984), people easily accept decisions of their subordinates, and so the impact of possible unjustified procedures in decisionmaking process has little effect on their behaviour and performance.

In order to examine the impact of the perceived level of justice on productivity, the regression analysis was done. The corresponding linear regression model that establishes the relationship between productivity, as dependent variable, and organizational justice (independent variable) has the following form:

$$
\begin{aligned}
y_{i}=2.479 .082,8+1.883 .248,6 \cdot x_{i} \\
y_{i}-\text { productivity } \\
x_{i}-\text { organizational justice }
\end{aligned}
$$

Thus, increase in the perceived level of organizational justice among employees in Serbia for 1 leads to an increase in earnings per employee for RSD 1,883,248.6 per year. However, this coefficient is not statistically significant, so the conclusion cannot be generalized, but it only applies to the observed sample of employees.

The results of the regression analysis are shown in Table 4.

Table 4 The impact of organizational justice on productivity in enterprises in Serbia

\begin{tabular}{l|r|r|r}
\hline \multirow{2}{*}{ (Constant) } & \multicolumn{2}{|c|}{ Beta } & \multirow{2}{*}{ Sig. } \\
\cline { 2 - 4 } & Unstandardized & \multicolumn{1}{c}{ Standardized } & \multicolumn{1}{c}{, 462} \\
\hline Distributive justice & 2714086,568 & &, 025 \\
\hline Procedural justice & 2350088,557 &, 216 &, 724 \\
\hline Interactional justice & 572483,917 &, 094 &, 398 \\
\hline $\mathbf{R}$ & 1086925,116 & & \\
\hline R Square &, 203 & & \\
\hline Adjusted R Square &, 141 & & \\
\hline Dependent variable: Productivity &, 123 & & \\
\hline
\end{tabular}

Source: Authors

As Table 4 shows, the greatest impact on productivity has distributive justice ( $\mathrm{St} . \mathrm{B}=0.216$ ). This coefficient is also statistically significant; therefore the second hypothesis of this paper is confirmed. The great importance that employees in Serbia give to distributive justice, which directly affects the performance of employees, can be explained by the fact that in Serbia the standard of living is extremely low and every form of reward has a major impact on the behavior of employees. For these reasons, if the rewards they receive for the effort invested is fairly estimated, they will work harder and achieve better performances. Otherwise, their results will be lower.

The data in Table 4 show that the impact of procedural justice and interactional justice is lower on productivity compared to the impact of distributive justice since their regression coefficients are not statistically significant. In other words, procedural justice and interactional justice have no statistically significant impact on employee productivity. Therefore, the hypotheses number three and four are rejected. This can be explained by the fact that there is a high level of irregularities, corruption and mistrust in Serbia for what are people used to it, so the organization's wrong behavior when making decisions, as well in interactions, is more or less expected and does not have a major impact on their behavior. Finally, it should be added that the shown model explains $12.3 \%$ of the variability in productivity.

\section{Conclusion}

Organizational justice is a very important dimension of every work environment because the level of fairness in decisions and processes directly reflects on the well-being of employees. The employees are particularly interested in decisions and processes related to rewarding, promoting, determining the possible surplus of employees, etc. Bearing in mind that organizational justice significantly influences the attitudes, behavior and performance of employees, 
it can also be seen as a kind of managerial tool for improving the overall organizational performance.

This paper analysed the impact of organizational justice on labour productivity measured by revenue per employee. The research has shown that there is a positive and significant link between these variables. This, further, suggests that if employees perceive a higher level of organizational justice, this will also have a positive effect on productivity.

Taking into account that the organizational justice is the constellations of three forms of justice: distributive, procedural, as well as interactional, we have examined the impact of each of them on the productivity. The results of the regression analysis showed that only distributive justice has a statistically significant impact on the productivity of employees in the surveyed enterprises.

Based on the results obtained in the research in terms of the perceived level of all three forms of organizational justice, certain recommendations for managers in domestic companies in order to make human resources management system more just, could be made. These recommendations are as follows:

- When advertising the need to fill an vacant positions, it is necessary that job description to be realistic and thereby contributing to the employees being adequately informed on all relevant aspects of the job;

- The selection process should be identical to all candidates and evaluate those aspects of competencies that are relevant to vacant posts;

- When deciding on rewards, promotions, etc., employees' merits should be respected, that is, employees should be rewarded in accordance with the results they have achieved. In addition, the same results should be followed by the same rewards for all employees in the given enterprise;

- When evaluating the performance of employees, the assessment should be objective;

- A high level of justice is also important in resolving conflict situations. In this situation it is necessary to demonstrate all of three forms of organizational justice with emphasis on the procedural dimension;
- All procedures in the company should be transparent and impartial. Otherwise, there will be a climate of uncertainty and instability, which in the long run can have negative consequences for the functioning of the company and its results.

Although this paper represents a certain contribution to the enrichment of the local literature fund in the field of organizational justice, it is not without limitations. These limitations are primarily related to the size of the sample. Namely, similar research carried out in this area in the world included much larger number of observation units, and therefore the results of the research were more relevant for making certain conclusions and recommendations. The second constraint related to the sample is the fact that the survey covered respondents from only one region in Serbia who, according to the level of development, is lagging behind in comparison to others. Namely, the level of development of a certain region can determine the characteristics of the corporate culture (especially the attitude towards the employees), as well as the development of the procedures applied in companies, which can influence the attitudes of the respondents regarding fairness in the organization.

Finally, one of the constraints of the paper is related to the fact that the attitudes of the respondents about the justice in the organization are correlated with the performances at the organizational level, not with performances at individual level. The correlation between employees' attitudes about justice in organization and performance would be more direct if the performance of employees whose attitudes about fairness are examined were observed.

These limitations of the paper at the same time address the way for future research. Namely, future research in this field should be conducted on a much larger sample that would include a larger number of observation units from all parts of Serbia. Also, in the focus of research that examines the impact of employees' perceptions of organizational justice on performance, performance made by employees should be observed. Individual performance could be determined within the self-assessments process by using a certain scale. Another possibility for performance assessment of employees is to be carried out by their superiors. Also, in the future it would be useful to investigate employees' attitudes about fairness in certain segments of the human resources management system as this 
would create the more accurate basis for implement measures for this system improvement.

Despite these limitations, we consider that this paper, however, will draw the attention of academic and professional public to the issue of justice in organizations, and will initiate some improvements in this area.sm

\section{References}

Adams, J. S. (1965). Inequity in social exchange. In: Berkowitz, L. (Eds.), Advances in experimental social psychology(pp. 267-299). New York: Academic Press. https://doi.org/10.1016/S0065-2601(08)60108-2.

Al-Zu'bi,H. A. (2010). A Study of Relationship between Organizational Justice and Job Satisfaction. International Journal of Business and Management, 5(12), 102-109.https://doi.org/10.5539/ijbm.v5n12p102.

Baldwin, S. (2006). Organizational justice. Institute of Employment Studies, pp. 1-13. Retrived February1, 2018, from

http://www.employmentstudies.co.uk/system/files/resou rces/files/mp73.pdf

Basu, E., Kumar Pradhan, R., \& Ram Tewari, H. (2017). Impact of organizational citizenship behavior on job performance in Indian healthcare industries: The mediating role of social capital. International Journal of Productivity and Performance Management, 66 (6),780-796

Bies, R. J., \& Moag, J. F. (1986). Interactional justice: Communication criteria of fairness. In R. J. Lewicki, B. H. Sheppard, \& M. H. Bazerman (Eds), Research on negotiations in organizations (pp.. 43-55). Greenwich: JAI Press.https://doi.org/10.1108/IJPPM-02-2016-0048.

Bin, A. S. (2016). The relationship between job satisfaction, job performance and employee engagement: An explorative study. Journal Issues in Business Management and Economics, 4 (1), 18https://doi.org/10.15739/IBME.16.001.

Cohen-Charash, Y., \&Spector, P. E. (2001). The role of justice in organizations: A meta-analysis. Organizational Behavior and Human Decision Processes, 86, 278321.https://doi.org/10.1006/obhd.2001.2958.

Colquitt, J. A. (2001). On the dimensionality of organizational justice: A construct validation of a measure. Journal of Applied Psychology, 86, 386400.https://doi.org/10.1037//0021-9010.86.3.386.

Cropanzano, R., \&Molina, A. (2015). Organizational justice. Y: J. D. Wright (Eds.), The International Encyclopedia of Social and Behavioral Sciences, Second Edition (pp. 379- 384). Oxford, UK: Elsevier Press.

Cropanzano, R., Bowen, D. E., \& Gilliland, S. W. (2007). The management of organizational justice. Academy of Management Perspectives, 21, 3448.https://doi.org/doi:10.5465/amp.2007.27895338.

Garg, P., \& Rastogi, R. (2006). New model of job design motivation employees Performance. Journal of Management Development, 25 (6), 572 587.https://doi.org/10.1108/02621710610670137.

Greenberg, J. (1987). A Taxonomy of Organizational Justice Theories. Academy of Management Review, 12(1), 9-22. https://doi.org/10.5465/amr.1987.4306437.

Hassan, A. (2002). Organizational justice as a determinant of organizational commitment and intention to leave. Asian Academy of Management Journal, 7 (2), 55-66.
Hofstede, G. (1984). Culture's consequences: International differences in work-related values. Newbury Park, CA: Sage.

Jafari, P. \& Bidarian, Sh. (2012). The relationship between organizational justice and organizational citizenship behavior. Procedia - Social and BehavioralSciences, 47,18151820.https://doi.org/10.1016/j.sbspro.2012.06.873.

Kalay, F. (2016). The Impact of Organizational Justice on Employee Performance: A Survey in Turkey and Turkish Context. International Journal of Human Resource Studies, 6 (1), 120.https://doi.org/10.5296/ijhrs.v6i1.8854.

Khan, R.M., Ziauddin, Jam, F.A., \&Ramay, M. I. (2010). The Impacts of Organizational Commitment on Employee Job Performance. European Journal of Social Sciences, 15 (3), 292-298.

Latham, G. P., \& Pinder, C. C. (2005). Work motivation theory and research at the dawn of the twenty-first century. Annual Review of Psychology, 56, 485516.https://doi.org/10.1146/annurev.psych.55.090902.1 $\underline{42105}$.

Leventhal, G. S. (1976). Fairness in social relationships. In: Thibaut, J. W., Spence, J. T.,\& Carson, R. C (Eds.), Contemporary Topics in Social Psychology(pp. 211-239). Morristown, NJ: General Learning Press.

Martin, A. J., \& Dowson, M. (2009). Interpersonal relationships, motivation, engagement, and achievement: Yields for theory, current issues, and educational practice. Review of Educational Research, 79 (1), 327-

365.https://doi.org/10.3102/0034654308325583.

Nasurdin, A. M., \& Khuan, S. L. (2011). Organizational justice, age, and performance connection in Malaysia. International Journal of Commerce and Management, 21 (3), 273-

290.https://doi.org/10.1108/10569211111165316

Niehoff, B.P.,\& Moorman, R.H. (1993). Justice as a Mediator of the Relationship between Methods of Monitoring and Organizational Citizenship Behavior. Academy of Management Journal, 36 (3), 527-556. http://dx.doi.org/10.2307/256591

Njambi, C. (2014). Factors influencing employee motivation and its impact on Employee Performance: a case of AMREF health Africa in Kenya. Unpublished Thesis, Retrived March 1, 2018, from http://erepo.usiu.ac.ke/bitstream/handle/11732/77/Carol .pdf?sequence $=1$

Rynes, S. L., Gerhart, B., \& Minette, K. A. (2004). The Importance of Pay in Motivation: Discrepancies between What People Say and What they Do. Human Resource Management, 43 (4), 381394.https://doi.org/10.1002/hrm.20031.

Sharon, S. \& Kubala, P. (2018). Social Justice in the Workplace: Are On-Demand Companies Exploiting Current Regulatory Ambiguities and Workforce Precarity? Psychosociological Issues in Human Resource Management, 6(1), 166171,https://doi.org/10.22381/PIHRM6120188.

Sponte Piştalu, M. (2018). Cognitive Performance and Labor Market Outcomes: Evidence from the U.S. Economics, Management, and Financial Markets, 13(2), 70-75.https://doi.org/10.22381/EMFM13220185.

Turnley, W. H., \& Feldman, D. C. (1999). The impact of psychological contract violations on exit, voice, loyalty, and neglect. Human Relations, 52 (7), 895-922. https://doi.org/10.1177/001872679905200703. 
$\triangle$ Correspondence

Blljana Đorđević

University of Niš, Faculty of Economics

Trg kralja Aleksandra Ujedinitelja 11, 18105 Nišs, Serbia

E-mail: biljana.djordjevic@eknfak.ni.ac.rs 